\title{
Comparison of Seam Strength between Dyed and Un-Dyed Gabardine Apparels: A Research on Lapped \& Superimposed Seam
}

\author{
Kaniz Farhana1, Md. Syduzzaman²*, Dilruba Yeasmin ${ }^{3}$ \\ ${ }^{1}$ Department of Apparel Engineering, Faculty of Fashion Design \& Apparel Engineering, Bangladesh University \\ of Textiles, Dhaka, Bangladesh \\ ${ }^{2}$ Department of Textile Engineering Management, Faculty of Textile Management \& Business Studies, \\ Bangladesh University of Textiles, Dhaka, Bangladesh \\ ${ }^{3}$ Central Capacity Planning, Next Sourcing Limited, Dhaka, Bangladesh \\ Email: kfarhana81@yahoo.com, ${ }^{*}$ sayeed33tex@gmail.com, ruba yeasmin@yahoo.com
}

Received 10 July 2015; accepted 22 August 2015; published 25 August 2015

Copyright (C) 2015 by authors and Scientific Research Publishing Inc.

This work is licensed under the Creative Commons Attribution International License (CC BY).

http://creativecommons.org/licenses/by/4.0/

(c) () Op Open Access

\section{Abstract}

Today is the golden age of fashion. Fashion garments and apparels have been used everywhere to cope with the fashion era. These fashion garments and apparels are made of the fabrics of various structures and components through various processes. Among them gabardine is one of the most remarkable type of fabric and apparel dyeing is the latest process used for fashion apparel. From this research, the seam strength variations between dyed and un-dyed gabardine apparels after conceding the garment dyeing process can be known. It is a comparative research work which will deliver very effective knowledge about various types of seam, seam strength and seam performance. For comparative study, many dummy apparels body have been produced as samples which are dyed in Hams washing and dyeing limited. After that all samples have tested in Thermax woven dyeing laboratory. Since Bangladesh is a very potential fashion market and the fashion garments are being manufactured more and more. Hence the fashion trend is rapidly going to garments dyeing from conventional fabric/yarn dyeing processes. Gradually garments dyeing order are increasing higher to higher.

\section{Keywords}

Seam, Seam Strength, Gabardine Apparel, Dyed Apparel, Un-Dyed Apparel, Apparel Dyeing

\footnotetext{
*Corresponding author.

How to cite this paper: Farhana, K., Syduzzaman, M. and Yeasmin, D. (2015) Comparison of Seam Strength between Dyed and Un-Dyed Gabardine Apparels: A Research on Lapped \& Superimposed Seam. Journal of Textile Science and Technology, 1, 75-84. http://dx.doi.org/10.4236/itst.2015.12008
} 


\section{Introduction}

Apparel is one of the fundamental needs of mankind's living. So it's being got more and more priority day by day. This basic apparel has come up to the fashion today with the chronological evolution of fashion. Apparel or garment industry includes a diversity of these fashion products to meet the demand. Nowadays the latest technologies are being applied in apparel industries. Today's fashion and apparel market is highly competitive and to sustain in this market, fashion producers mainly rely on the quality issues not on prices merely. And from this aspects raw material properties, sewing performance and seam quality become very important.

Fabric and sewing thread is the basic raw material of apparel industry. Characteristics of the raw material influence the seam quality of the garment. The apparel designers are primarily interested in the raw material properties for high seam quality and consumer is mainly interested in appearance, comfort, and wears the ability of the garment. Proper selection of raw material not only gives comfort to the wearer but also helps in smooth working of manufacturing process and leads to defect free garment [1].

Since the vast majority of seams in a garment are held together by sewing thread, it is important to recognize that $50 \%$ of the responsibility of the garment's performance is dependent on sewing thread \& other parameters [2].

A large variety of sewing threads is used in clothing industry. The majority of the sewing threads used by the clothing industry are made from cotton and polyester fiber [3]. Threads made from natural fibers such as linen and silk and certain manmade fibers, for example nylon, acrylic and viscose are also used in clothing industry [4].

Many factors influence the quality of seams. These factors can be classified into four principal origins: speed, needle, thread and fabric. It is found that fundamental interactions between these factors still exist [5]. For the purpose of making good seam, great number of techniques has been developed until today but nothing has been as successful as sewing process. Stitch is placing the sewing materials like fabrics with in and out by needle. Different stitches and stitch types are being used for flexible materials like knitted apparels and suits; they are being used for less flexible knitted products and for sewing relatively inflexible materials like woven fabrics as well. Despite of recent developments on automation of general set up; sewing threads are still irreplaceable material in apparel sector. The mistakes arisen from the sewing threads have been eliminated by new studies which are performed by manufacturers. As a result, technological developments: smooth, steady and strong sewing threads provide advantages for all stitch types [6].

\subsection{Seam}

A seam consists of a series of stitches joining two or more plies of a material or materials. A seam is used for joining or assembling materials in the production of an article [7].

A seam is the application of a series of stitches or stitch types to one or several thickness of materials. Seam line is a stitch line of a seam; it is usually parallel to and always an appearance of the seams affects overall attractiveness of a garment. Straight, neat, smooth, even seams that are not twisted, ropey, or rippled contribute to aesthetics [8].

According to British Standard 3870, there are eight types of seam:

- Class 1 (superimposed seam);

- Class 2 (lapped seam);

- Class 3 (bound seam);

- Class 4 (flat seam);

- Class 5 (decorative seam);

- Class 6 (edge neatening seam);

- Class 7;

- Class 8 [9].

\subsubsection{Seam Class 1 (Superimposed Seam)}

The simplest seam type within the class is formed by superimposing the edge of one piece of material on another [9].

The superimposed seam (Figure 1) is the most commonly used method of seaming; however its overall appearance can be very different when all the necessary factors have been balanced. The basic characteristic of a 
superimposed seam is that the seam allowance is exactly the same on top and bottom ply [8].

\subsubsection{Seam Class 1 (Lapped Seam)}

The simplest seam type in this class is formed by lapping two pieces of material. The seams in this have uneven seam allowances; therefore the pattern cutting and garment assembly has to be performed with extra care to ensure that the garment fits together correctly. In a nut-shell the seam allowance on one side overlaps the other, hence the name lapped seam (Figure 2) [8].

\subsection{Seam Strength}

The seam strength of a sample refers to the force acting upon a seam, at the time of fabric failure along the line of needle penetration. Seam strength refers to the load required to break a seam. Two pieces of woven fabric are joined by a seam and if tangential force is applied the seam line, rupture ultimately occurs at or near the seam line. Every seam has two components, fabric \& sewing thread. Therefore, seam strength must result from the breakage of either fabric or thread or in more cases, both simultaneously. Research has revealed that the load required to rupture the seam is usually less than that required to break the unsewn fabric [11] [12].

Few factors that determine the strength of a seam include:

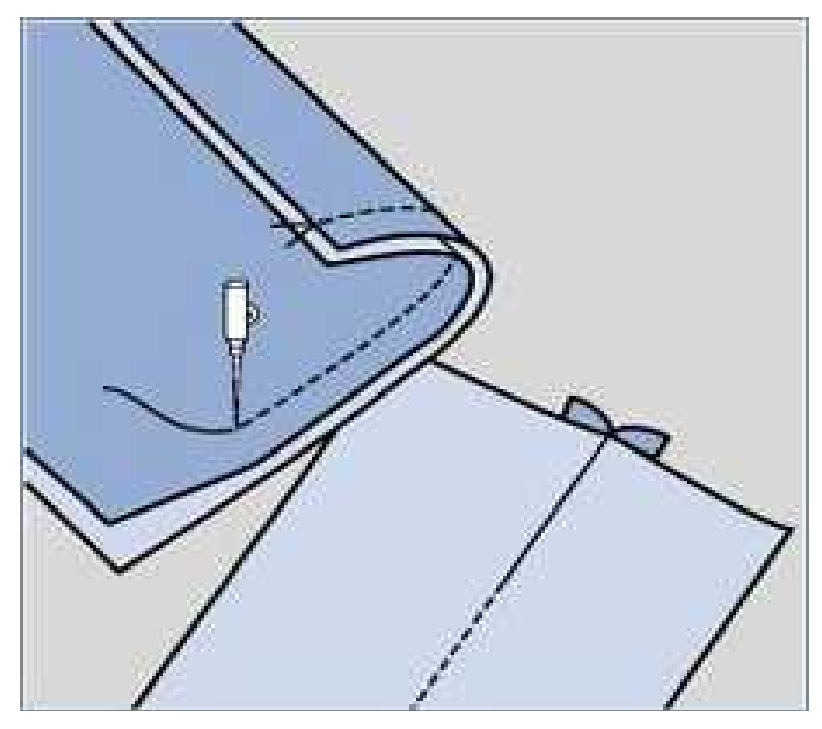

Figure 1. Superimposed seam [10].

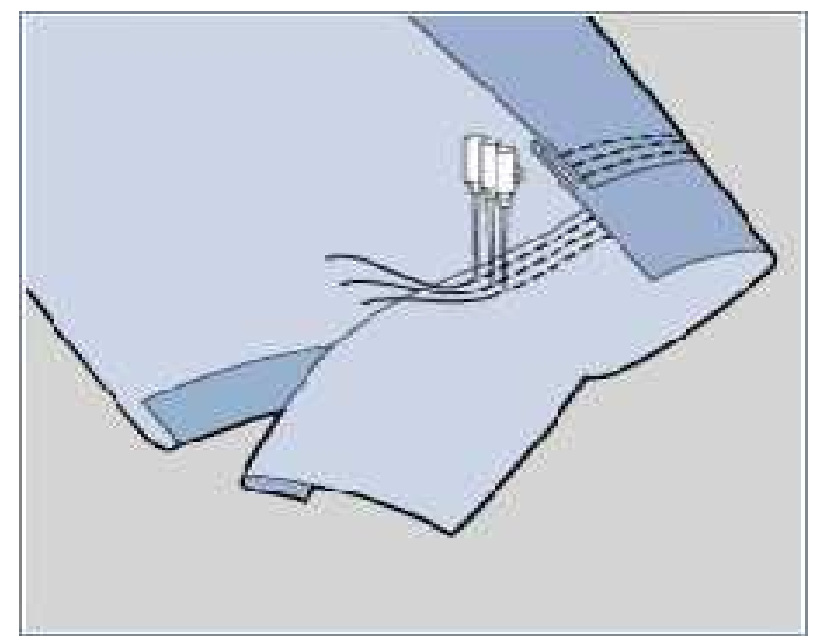

Figure 2. Lapped seam [10]. 
- Fabric Type, Weight, Strength, Durability;

- Thread Fiber Type, Construction, and Size;

- Stitch and Seam Construction;

- Stitches per Inch (A \& E).

When two pieces of woven fabric are joined by a seam and an increasing force is applied to the assembly at right angles to the seam line, rupture ultimately occurs at or near the seam line and at a load usually less than that required to break the unsewn fabric. Since every seam has two components, namely the fabric and the sewing thread, seam failure must result from the breakage of either the fabric or the thread or, in rare cases, both simultaneously [9].

In case of a fabric break, two different mechanisms are possible. The fabric may actually break, perhaps as a result of being weakened by needle damage, and the seam will rupture [13].

\subsection{Gabardine}

Gabardine is a tightly woven warp-faced twill weave fabric. Warp-faced fabrics have more warp or lengthwise yarns on the surface of the fabric than filling or crosswise yarns. Twill weave fabrics show a diagonal wale, or raised line, on their surface. The fine wale is closely spaced, slightly raised, distinct, and obvious only on the fabric's face. The wale angle in gabardine is 45 or 63 degrees. Gabardine always has many more warp than filling yarns, often twice as many warp yarns as filling yarns. Fabric weights range from 7 ounces per square yard to 11 ounces per square yard. Fabric density ranges from 76 warp ends per inch (epi) by 48 filling picks per inch (ppi) to 124 epi by 76 ppi. The combination of the weave structure, yarn size, and warp to filling ratio creates the wale angle. A steep (63 degree angle) twill gabardine is often used in men's wear while a regular (45 degree angle) twill gabardine is often used in women's wear. In the most common interlacing patterns the warp crosses two filling yarns before going under one filling $(2 \times 1)$ or the warp crosses two fillings before going under two fillings $(2 \times 2)$ to create right-hand twills in which the wale line moves from the lower left to the upper right [14].

\subsection{Apparel Dyeing}

In the world of fast fashion when time to market is paramount, garment dyeing post make up is increasingly adopted by manufacturers [15].

Apparel dyeing has implications for the finished quality of the garments and this bulletin explains how to minimize the negative impact of this process on general seam appearance and sewing related issues. We explain the dos and don'ts of sewing post dyed garment [16].

Apparel dyeing procedure has seeming proliferated itself in dyeing and finishing in recent years. Necessities of quicker fashion changes reduction in final cost of production and a better aesthetic of dyed garment have enhanced the need for apparel dyeing. Benefits of articles by garment dyeing procedure revolve around quick and inventory control. Processing lead time has considerably been reduced by almost 33\% through garment dyeing technique, since color is added late in the apparel process chain. Augmentation of easy monitoring techniques, replenishment of stocks with newer trend and fashion, reduced level of stock holding, complete computerized control and bar coding have recently emerged out as additional features. Apparel dyeing can be done by exhaust and continuous [17].

\section{Methodology}

For the purpose of this research, different jobs have been done in different work places. To complete this work, the whole work has been done in three stages in three different laboratories. Firstly, apparel sewing (leg panel) has been done in Apparel Manufacturing Engineering laboratory, Bangladesh University of Textiles, then apparel dyeing has been done in apparel dyeing factory named Hams Washing \& Dyeing Limited, Tejgaon I/A, Dhaka and finally apparel testing that is seam strength test has been done in a Testing Lab of Thermax Woven Dyeing Limited, Norsingdi. So this experimental work has been done in three steps as bellows:
1) Sewing;
2) Dyeing;
3) Testing. 


\section{Experimental Work}

\subsection{Sewing}

\section{Sample selection:}

- Apparel: Trouser/Pant (leg panel);

- Fabric: Twill fabric, $100 \%$ cotton;

- Sewing Thread: Two types; Tex 60, Tex 105; $100 \%$ cotton. Specifications:

Table 1 shows the Sample Fabric;

Table 2 shows the Sample Sewing Thread;

Table 3 and Table 4 show variable parameters for this work.

\subsection{Dyeing}

Direct dyestuff has been used.

Process flow chart of Dyeing with Direct Dyestuff:

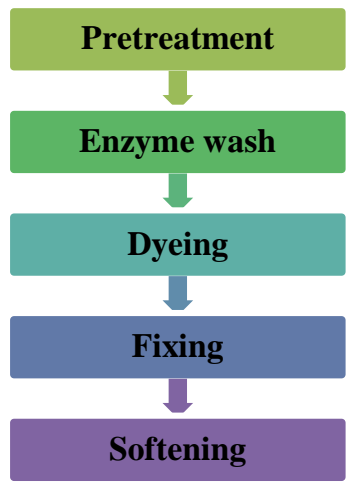

Table 1. Specification of sample gabardine fabric which has been used in this experiment.

\begin{tabular}{cc}
\hline Parameters & Gabardine \\
\hline Material & $100 \%$ Cotton \\
Fabric Construction & Twill $1 / 3$ \\
Yarn, Warp/cm & 52 \\
Yarn, Weft $/ \mathrm{cm}$ & 20 \\
Mass (gm $\left./ \mathrm{m}^{2}\right)$ & 217 \\
Yarn Count (Warp) & 20 's \\
Yarn Count (Weft) & 16 's \\
\hline
\end{tabular}

Table 2. Specification of sample sewing thread which has been used for making seam in this experiment.

\begin{tabular}{cccc}
\hline Tex number of sewing thread & Ticket number & Count (Ne) of sewing thread & Length (M) \\
\hline 60 & 030 & $30 / 3$ & 5000 \\
105 & 018 & $18 / 3$ & 5000 \\
\hline
\end{tabular}

Table 3. Different variables taken into consideration for this experimental research.

\begin{tabular}{cc}
\hline Needle size & 16,18 \\
\hline Seam & Lapped, Superimposed \\
Stitch & Class 400, Class 500 \\
\hline
\end{tabular}


Table 4. Numbering of seam with specific variable details.

\begin{tabular}{|c|c|c|c|c|c|}
\hline Sample No. & Sewing Thread Linear Density & Stitch per Inch & Needle Size & Stitch Class & Seam Type \\
\hline 1 & Tex 60 & $13-14$ & 16 & 400 & \multirow{23}{*}{ Superimposed seam } \\
\hline 2 & Tex 60 & $10-11$ & 16 & 400 & \\
\hline 3 & Tex 60 & $7-8$ & 16 & 400 & \\
\hline 4 & Tex 60 & $13-14$ & 18 & 400 & \\
\hline 5 & Tex 60 & $10-11$ & 18 & 400 & \\
\hline 6 & Tex 60 & $7-8$ & 18 & 400 & \\
\hline 7 & Tex 105 & $13-14$ & 16 & 400 & \\
\hline 8 & Tex 105 & $10-11$ & 16 & 400 & \\
\hline 9 & Tex 105 & $7-8$ & 16 & 400 & \\
\hline 10 & Tex 105 & $13-14$ & 18 & 400 & \\
\hline 11 & Tex 105 & $10-11$ & 18 & 400 & \\
\hline 12 & Tex 105 & $7-8$ & 18 & 400 & \\
\hline 13 & Tex 60 & $13-14$ & 16 & 500 & \\
\hline 14 & Tex 60 & $10-11$ & 16 & 500 & \\
\hline 15 & Tex 60 & $7-8$ & 16 & 500 & \\
\hline 16 & Tex 60 & $13-14$ & 18 & 500 & \\
\hline 17 & Tex 60 & $10-11$ & 18 & 500 & \\
\hline 19 & Tex 105 & $13-14$ & 16 & 500 & \\
\hline 20 & Tex 105 & $10-11$ & 16 & 500 & \\
\hline 21 & Tex 105 & $7-8$ & 16 & 500 & \\
\hline 22 & Tex 105 & $13-14$ & 18 & 500 & \\
\hline 23 & Tex 105 & $10-11$ & 18 & 500 & \\
\hline 24 & Tex 105 & $7-8$ & 18 & 500 & \\
\hline
\end{tabular}

\subsection{Testing}

\section{Garments Seam Strength Testing:}

Test Method: ISO 13935-2: 1999.

Textiles—Seam tensile properties of fabrics and made-up textile articles—Part 2: Determination of maximum force to seam rupture using the grab method.

\section{Result \& Discussion}

\subsection{Effect of the Types of Seam \& Stitch on Seam Strength}

There is a significant difference of seam strength between un-dyed \& dyed samples for both lapped \& superimposed seam.

\subsubsection{Lapped Seam}

Table 5 shows the loss of seam strength between un-dyed and dyed samples. In case of gabardine apparels, the loss of seam strength of dyed lapped seam is varying from 5 to above 10 in percent.

By this Figure 3 (Table 5), it has been observed that the samples off odd number beginning from 1 to 23 are made by Lapped seam. Each and every sample shows 2 types of numerical values of seam strength measured by seam strength tester in Newton (N). Axis X expresses the sample number \& Axis Y expresses the seam strength. Here the lapped seam strength always less in dyed samples. 
As per Figure 3 above, it is clearly understood that the difference of seam strength or the loss of seam strength between un-dyed \& dyed samples.

\subsubsection{Superimposed Seam}

Table 6 shows the loss of superimposed seam strength between un-dyed and dyed samples. In case of gabardine apparels, the loss of superimposed seam strength is varying from above 9 to 13 percent shown in Table 6 . The loss of seam strength of superimposed seam is higher than lapped seam.

By this Figure 4, Table 6, it has been observed that the samples off odd number beginning from 25 to 47 are

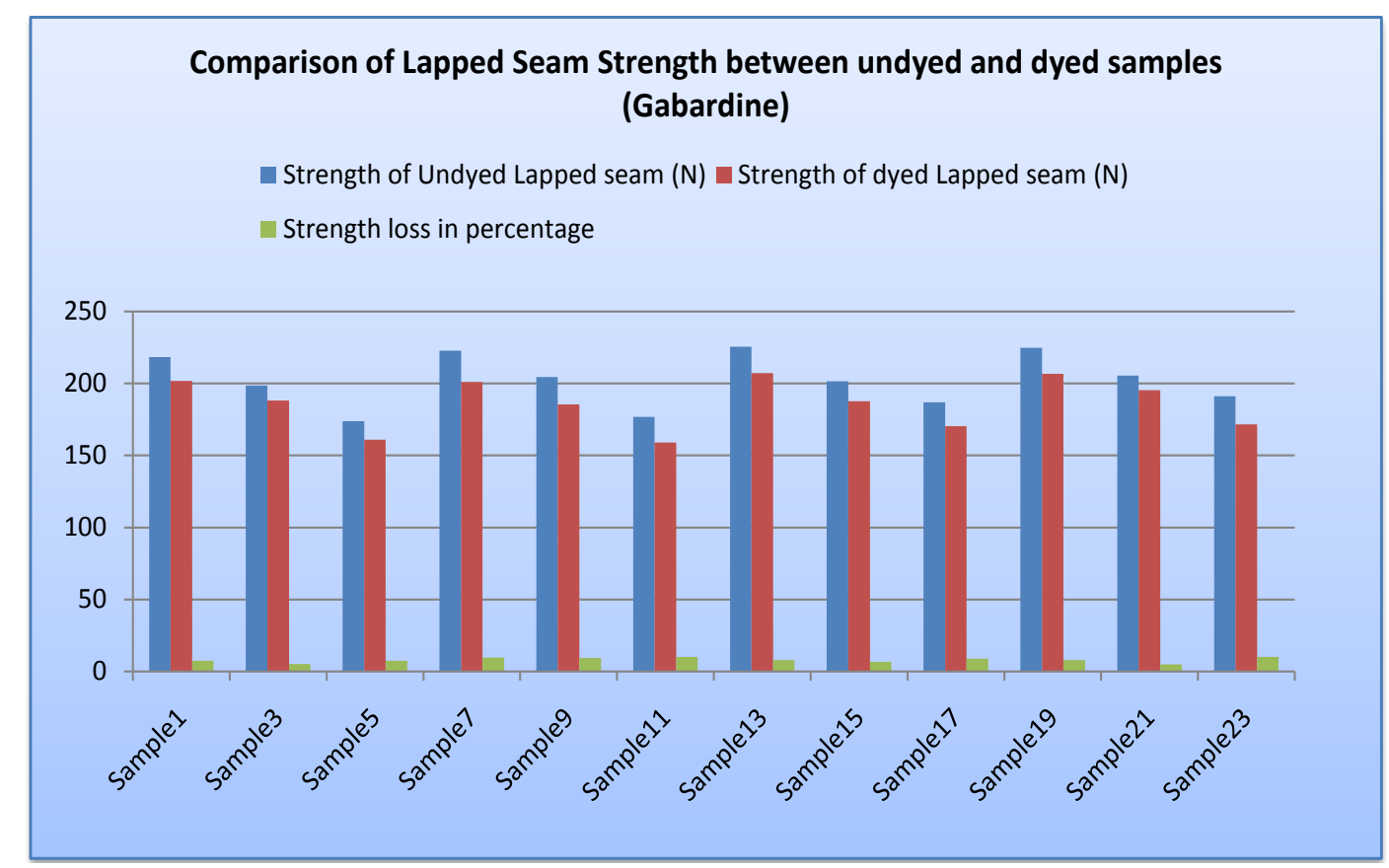

Figure 3. Comparison of lapped seam strength in Newton $(\mathrm{N})$ between un-dyed and dyed samples.

Table 5. Comparison of lapped seam strength between dyed and un-dyed gabardine found from research.

\begin{tabular}{|c|c|c|c|c|c|}
\hline $\begin{array}{l}\text { Sewing Thread } \\
\text { Linear Density Tex }\end{array}$ & Needle Size & Sample No. & $\begin{array}{l}\text { Lapped Seam Strength in } \\
\text { Newton }(\mathrm{N}) \text { before Dyeing }\end{array}$ & $\begin{array}{l}\text { Lapped Seam Strength in } \\
\text { Newton }(\mathrm{N}) \text { after Dyeing }\end{array}$ & $\begin{array}{l}\text { Lapped Seam Strength } \\
\text { Loss in Percentage }\end{array}$ \\
\hline & & 1 & 218.3 & 201.9 & 7.5 \\
\hline & 16 & 3 & 198.5 & 188.3 & 5.1 \\
\hline \multirow[t]{6}{*}{60} & & 5 & 173.8 & 161.1 & 7.3 \\
\hline & & 7 & 222.7 & 201 & 9.7 \\
\hline & 18 & 9 & 204.6 & 185.4 & 9.3 \\
\hline & & 11 & 176.9 & 158.9 & 10.1 \\
\hline & & 13 & 225.6 & 207.3 & 7.8 \\
\hline & 16 & 15 & 201.5 & 187.6 & 6.8 \\
\hline \multirow[t]{4}{*}{105} & & 17 & 187 & 170.3 & 8.9 \\
\hline & & 19 & 224.8 & 206.8 & 8 \\
\hline & 18 & 21 & 205.6 & 195.3 & 5 \\
\hline & & 23 & 191.1 & 171.5 & 10.2 \\
\hline
\end{tabular}


made by superimposed seam. Every sample shows 2 types of numerical values of seam strength measured by seam strength tester in Newton (N). Axis X represents the sample number \& Axis Y expresses the seam strength. Here it has been found that the superimposed seam strength always less in dyed samples.

As per Figure 4, it has been clearly observed that the difference of seam strength or the loss of seam strength between un-dyed \& dyed samples.

By comparing 2 tables (Table 3 \& Table 4), the loss of seam strength is not equal between lapped seam \& superimposed seam. The loss of seam strength of superimposed seam is always higher than the lapped seam which can be representing by line diagram in Figure 5. Both of lapped and superimposed seam shows the fluc-

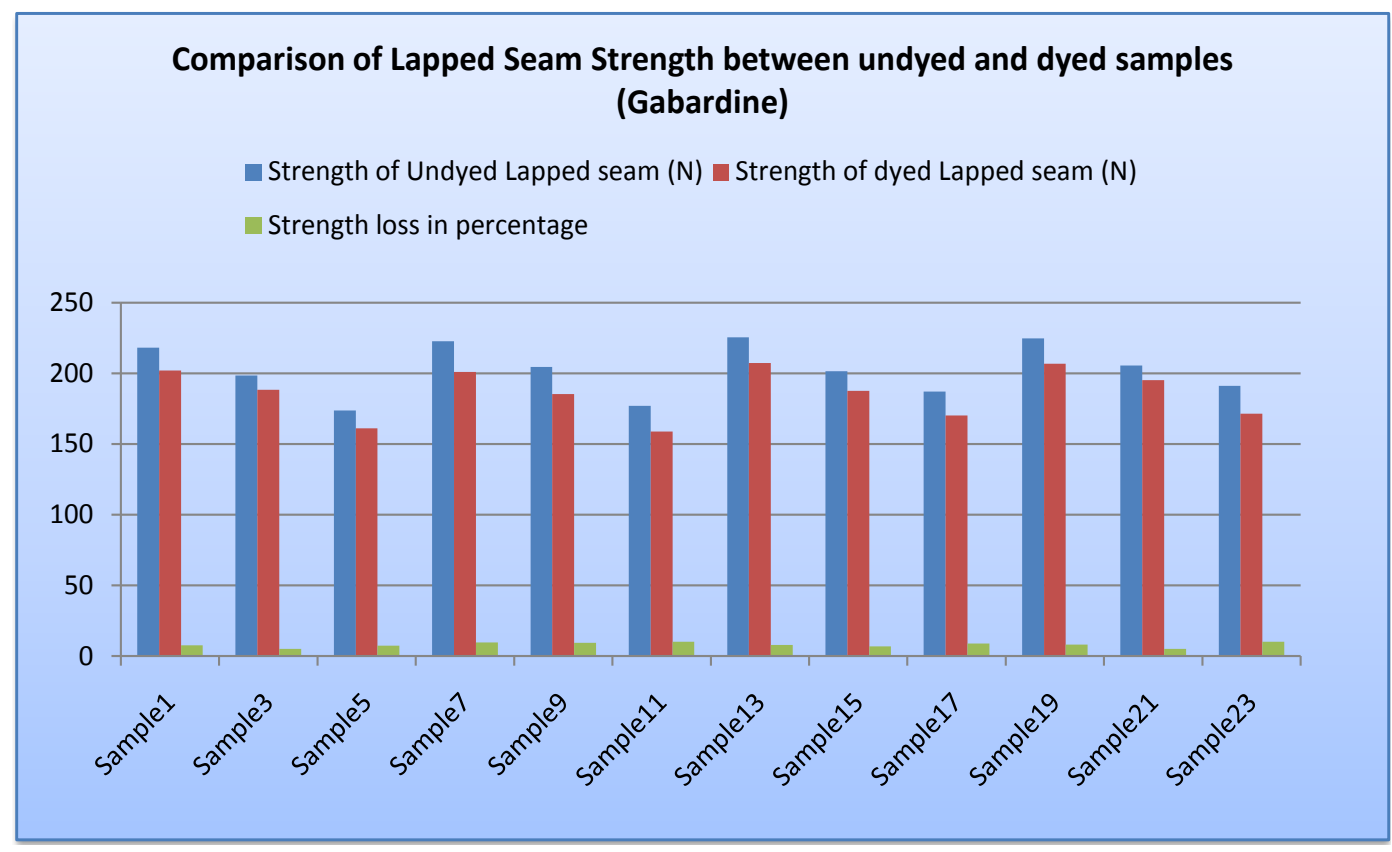

Figure 4. Comparison of superimposed seam strength in Newton $(\mathrm{N})$ between un-dyed and dyed samples.

Table 6. Comparison of superimposed seam strength between dyed and un-dyed gabardine found from research.

\begin{tabular}{|c|c|c|c|c|c|}
\hline $\begin{array}{l}\text { Sewing Thread Li- } \\
\text { near Density Tex }\end{array}$ & Needle Size & Sample No. & $\begin{array}{l}\text { Superimposed Seam } \\
\text { Strength in Newton (N) } \\
\text { before Dyeing }\end{array}$ & $\begin{array}{l}\text { Superimposed Seam } \\
\text { Strength in Newton (N) } \\
\text { after Dyeing }\end{array}$ & $\begin{array}{l}\text { Strength Loss in } \\
\text { Percentage }\end{array}$ \\
\hline \multirow{5}{*}{60} & \multirow{3}{*}{16} & 25 & 212.3 & 189.5 & 10.8 \\
\hline & & 27 & 196.7 & 176.2 & 10.4 \\
\hline & & 29 & 172.8 & 153.2 & 11.3 \\
\hline & \multirow{3}{*}{18} & 31 & 216.9 & 188.9 & 12.9 \\
\hline & & 33 & 195.4 & 171.5 & 12.2 \\
\hline \multirow{7}{*}{105} & & 35 & 171.9 & 151.4 & 11.9 \\
\hline & \multirow{3}{*}{16} & 37 & 222.6 & 193.5 & 13 \\
\hline & & 39 & 200.2 & 179.8 & 10.1 \\
\hline & & 41 & 176.9 & 151.8 & 14.1 \\
\hline & \multirow{3}{*}{18} & 43 & 224.5 & 200.9 & 10.5 \\
\hline & & 45 & 197.3 & 179.3 & 9.1 \\
\hline & & 47 & 169.3 & 152.8 & 9.7 \\
\hline
\end{tabular}




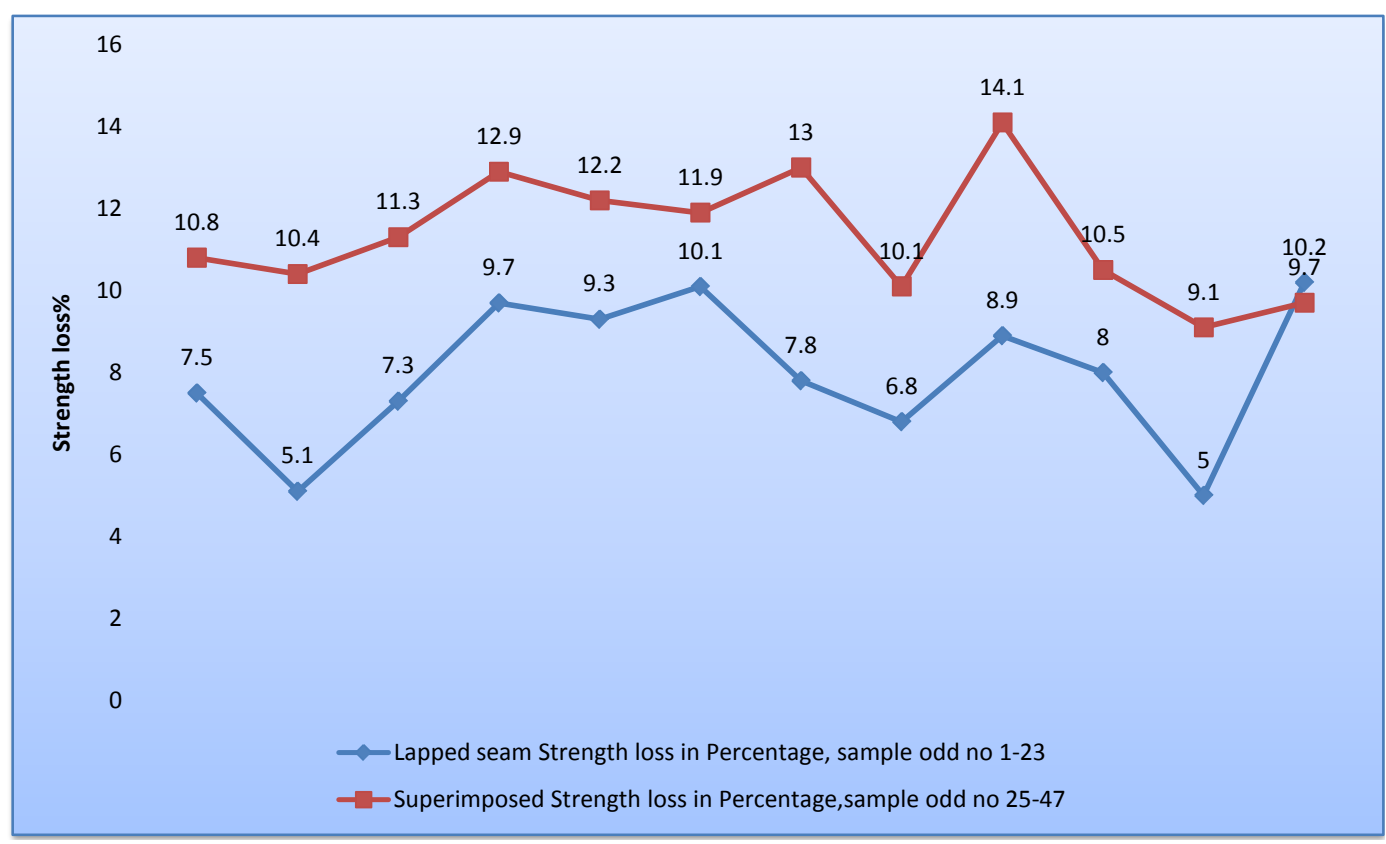

Figure 5. Comparison of seam strength loss in percent between lapped \& superimposed seam.

tuated trend of loss of seam strength after apparel dyeing. Lapped seam shows downward fluctuated trend whereas superimposed seam shows upward increasing trend.

\section{Discussion}

For lapped seam, the loss of seam strength between un-dyed \& dyed samples is more or less $5 \%-10 \%$.

For superimposed seam, the loss of seam strength between un-dyed \& dyed is more or less $9 \%-13 \%$.

It is noticeably observed that the loss of seam strength of superimposed seam is higher than the lapped seam.

\section{Conclusion}

At the end of this research work, we can conclude that, seam strength of dyed apparels is less than that of undyed apparels. It is because of undergoing various stages in dyeing process. Different factors of sewing influence the seam strength on dyed apparels individually. The performance of apparels mainly depends on seam and stitch as well as different sewing factors. Here we also find that loss of seam strength for lapped seam is less than that of superimposed seam. So the fashion apparels in which lapped seam is mainly used, are more durable. To cope with the modern fashion era, we have to go through the fashion garments/apparels. And we also need to concentrate on the processes involved in making this fashion garments.

\section{References}

[1] Kothari, V.K. (1999) Testing and Quality Management. IAFL Publications, New Delhi.

[2] Anderson, K. (2009) Selecting the Correct Sewing Thread. 1-5. www.techexchange.com

[3] Standard: ISO 4915:1991. Textiles, Stitch Guide.

[4] Standard Practice for Stitch and Seam ${ }^{1}$. Designation: D 6193-97 (Reapproved 2004), ASTM international.

[5] Kordoghli, B., Cheikhrouhou, M. and Saidene, C.K. (2009) Mechanica of Seams on Treated Fabrics. Autex Research Journal, 9, 87. http://www.autexrj.org/No3-2009/87.

[6] Bharani, M., Shiyamaladevi, P.S.S. and Mahendra Gowda, R.V. (2012) Characterization of Seam Strength and Seam Slippage on Cotton Fabric with Woven Structures and Finish. Research Journal of Engineering Sciences, 1, 41-50.

[7] Kornfel, L.L. (1952) A Study of the Fundamental Factors That Affect Seam Strength. Georgia Institute of Technology, Atlanta.

[8] Seetharam, G. and Nagarajan, L. (2014) Evaluation of Sewing Performance of Plain Twill and Satin Fabrics Based on 
Seam Slippage Seam Strength and Seam Efficiency. Journal of Polymer and Textile Engineering, 1, 9-21.

[9] Carr, H. and Latham, B. (1995) The Technology of Clothing Manufacturing. Blackwell Scientific Publications, Oxford.

[10] http://www.coatsindustrial.com/en/information-hub/apparel-expertise/seam-types

[11] Behera, B.K. and Sharma, S. (1998) Low Stress Behavior and Sewability of Suiting and Shirting Fabrics. Indian Journal of Fiber and Textile Research, 23, 233-241.

[12] Choudhury, P.K. (2000) Improvement in Seam Performance of Jute Bags. Indian Journal of Fiber and Textile Research, 25, 206-210.

[13] Gribaa, S., Amar, S.B. and Dogui, A. (2006) Influence of Sewing Parameters, upon the Tensile Behavior of Textile Assembly. International Journal of Clothing Science and Technology, 18, 235-246. http://dx.doi.org/10.1108/09556220610668581

[14] http://angelasancartier.net/gabardine

[15] (2014) Coats Sewing Solution; Seam types. Bulletin Post.

[16] (2014) Coats Sewing Solution; Sewing Post Dyed Garments. Bulletin Post.

[17] Chakraborty, J.N., Rudrajit, P. and Megha, P.R. (2005) Garment Dyeing. Indian Journal of Fibre \& Textile Research, 30, 468-476. 